\title{
TASMANIPATUS BARRETTI GEN. NOV., SP. NOV. AND T. ANOPHTHALMUS SP. NOV.: TWO NEW AND UNUSUAL ONYCHOPHORANS (ONYCHOPHORA: PERIPATOPSIDAE) FROM NORTHEASTERN TASMANIA
}

\author{
by H. Ruhberg, R. Mesibov, D.A. Briscoe and N.N. Tait \\ (with four plates)
}

RUHBERG, H., MESIBOV, R., BRISCOE, D.A. \& TAIT, N.N., 1991 (20:xii): Tasmanipatus barretti gen. nov., sp. nov. and $T$ anophthalrnussp. nov.: two new and unusual onychophorans (Onychophora: Peripatopsidae) from northeastern Tasmania. Pap. Proc. R. Soc. Tasm. 125: 7-10. https://doi.org/10.26749/rstpp.125.7 ISSN 0080-4703. Zoologisches Institut und Zoologisches Museum, Universitat Hamburg, Martin-Luther-King-I'latz 3, D-2000 Hamburg 13, Germany (HR); PO Box 431, Smithton, Tasmania, Australia 7330 (RM); and School ofBiological Sciences, Macquarie University, Sydney, New South Wales, Australia 2109 (DAB \& NNT).

Tasmanipatus gen. nov., Peripatopsidae Bouvier 1907, is characterised by eighreen dorsal plical folds on each body segment, in combination with a unique distribution of male crural papillae and a lack of pigmentation over all or most of the ventral body surface. The type species T. barrettisp. nov. is unique in relation to its combination of large size, uniform, patternless colouration, and well-developed crural papillae in both sexes. Tasmanipatus anophthalmus sp. nov. is unusual in lacking eyes and body pigmentation. The two species occur parapatrically in a small area in northeastern Tasmania. Their diagnostic features are described here.

Key Words: Onychophora, Tasmania, taxonomy, peripatus, velvet worm, Tasmanipatus.

\section{INTRODUCTION}

Two species of Peripatopsidae are currently recognised in Tasmania (Ruhberg 1985), the oviparous Ooperipatellus insignis (Dendy 1890) and the viviparous Euperipatoides leuckarti (Saenger 1869). Two new forms from the northeast of the state are described here and a new genus, Tasmanipatus, is erected to contain them. Detailed distributionsand habitat preferences are described in Mesibov \& Ruhberg (1991).

Specimens were collected in 1984-90 by one or more of the authors and their associates (for details, see Mesibov \& Ruhberg 1991) and preserved in 70-75\% ethanol or isopropanol. The bulk of the preserved material has been deposited at the Queen Victoria Museum and Art Gallery, Launceston, Tasmania. Specimens were loaned by the Museum for further study, and all type material will be stored there. Scanning electron micrographs were produced by HR in Hamburg.

\section{RESULTS}

Tasmanipatus gen. nov. (pls 1-4)

Type Species

Tasmanipatus barretti sp. nov., by original designation.

Etymology

The generic name is derived by combining Tasman-, referring to the geographic distribution of the new taxon, with -patus, the suffix of Peripatus.

\section{Distribution}

Tasmania, Australia. Only known from an area of approximately $800 \mathrm{~km}^{2}$ in northeastern Tasmania. For species distributions see Mesibov \& Ruhberg (1991).

Diagnosis

Tasmanipatusis a genus of Australian viviparous peripatopsid
Onychophora with 18 dorsal plical folds per body segment, male crural papillae on leg pairs 6-12 (occasionally also on leg pairs 13 and 14) and a lack of pigmentation over all or mosr of the ventral body surface.

\section{Differential Diagnosis}

Tasmanipatus is distinguished from all other known peripatopsid genera on the basis of a unique combination of characters (for comparisons see Ruhberg 1985).

It is distinguished from South African Peripatopsis and Opisthopatus in having 15 pairs of legs and well-developed receptacula semines. Leg number and possession of basal foot papillae distinguish it from Chilean Metaperipatus and Paropisthopatus, and from New Guinean Paraperipatus. Presence of basal foot papillae and male crural glands allow distinction of Tasmanipatus from New Zealand Peripatoides.

Tasmanipatus is separable from all other Australian genera, except Austroperipatus, in its possession of basal foot papillae. In addition, it is distinguished from Mantonipatus in having 18 rather than 12 plical folds, and in lacking a characteristic pattern of several colours. From Ooperipatus and Ooperipatellus it is further distinguished by being viviparous, and from Cephalofovea (Ruhberg et al. 1988) by lacking a cephalic pit. Tasmanipatus and Austroperipatus differ in the presence of an ovipositor in females of the latter genus.

\section{Description}

Viviparous peripatopsid. Leg number constant within species, last leg pair well developed, with claws. Foot with 2 basal and 3 distal papillae. Pygidium (= anal cone) as long as, or longer than last pair of legs. Genital pore variable in form (pls 2, 4). Outer blade of mandibles lacking accessory tooth. Slime glands extremely ramified, more than in most other Peripatopsidae. Male. with crural glands corresponding with crural papillae, lying within the leg cavity; anterior accessory genital papillae on leg pair 15, with corresponding anterior accessory glands (= modified crural glands) lying within the body cavity as long, slender tubes; posterior accessory genital glands (= anal glands or modified segmental organs) opening 
separately into $\mathrm{V}$-or Y-shaped slits between genital pore and anus; anterior and posterior accessory glands coiled around each orher; testes extremely long and twisted, unpaired genital tract long, spermatophores slender. Female. with paired ovaries which are long, flat, looped and closely attached to the pericardial septum; ovarial eggs exogenous; receptacula semines present; uterine cmbryos of about the same developmental stage, dorsal region of embryos supplied with a solid mass of yolk extending from the head to the anus.

\section{Tasmanipatus barrettisp. nov. (pls 1,2)}

1938 Ooperipatus insignis, Barrett, Vict. Nat. 55: 11-12 (with two photographs).

1989 "Peripatus", Tait \& Briscoc, Aust. Nat. Hist. 22: 574 (coloured photograph of live specimen).

1989 "Giant velvet worm". Local common name for this species.

1990 "Giant velvet worm", Mesibov, Tasforests 1991(July 1990): 53-56.

1991 "Giant velvet worm", Mesibov \& Ruhberg, Pap. Proc. R. Soc. Tasm. 125: 11-16.

Holotype

\%, Tasmania, Evercreech Rivulet, EQ813163, leg. R. Mesibov, 7 Sep 1987 (size in preservative $36.4 \mathrm{~mm}$; dissected).

Collection of the Queen Victoria Museum and Art Gallery, Launceston.
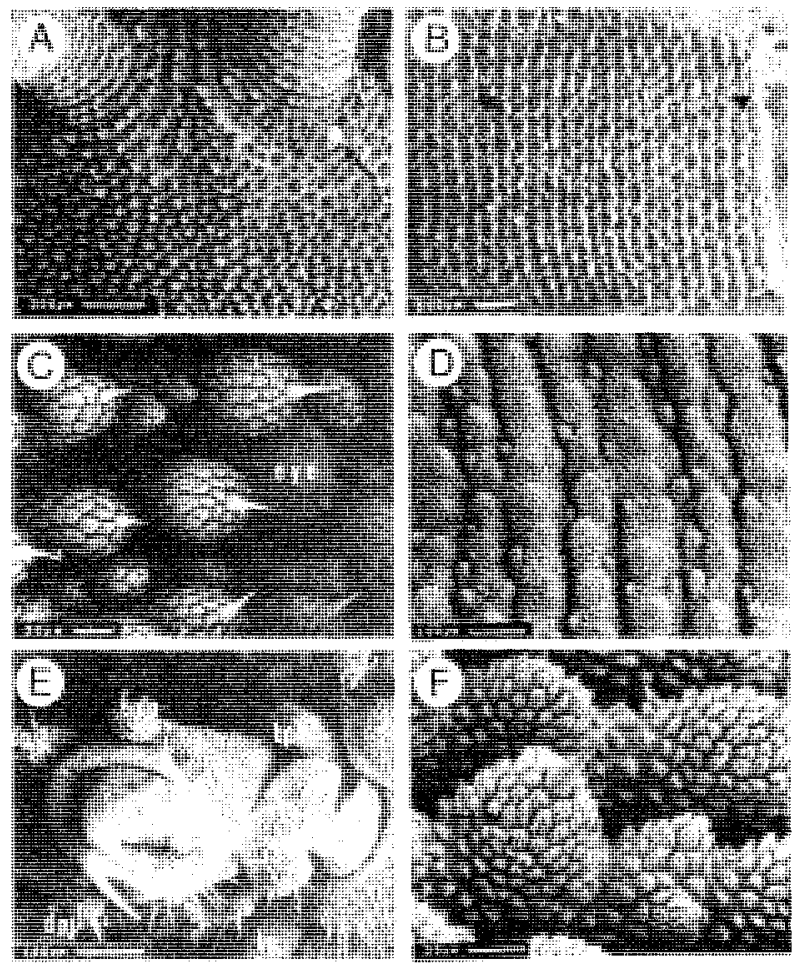

PLATE 1

Tasmanipatus barretti, gen. nov., sp. nov. (A) SEM of the dorsal head with eye (arrow). (B) SEM of 18 segmental plical folds (between arrowheads). (C) SEM of eye and surrounding papillae. (D) SEM of plical folds with bigger primary and smaller secondary papillae. (E) SEM of foot with two basal (bp) and three distal (dp) papillae. (F) SEM of primary dorsal papilla with eight ranks of scales (arrow).
Allotype

q, same data as for holotype $(23.3 \mathrm{~mm}$, dissected).

Paratypes

20 , same data as for holotype. 28,20 , Scamander River FQ046099, leg. RM, 17 Nov 1988. 28, 2 , 1 juv., Salters Gully, FQ049003, leg. RM, 3 Nov 1988. 38 ", 1 q, 1 juv., Basin Creek, FQ036179, leg. RM, 29 Oct 1988. 5Q, Ericksons Road, EQ938253, leg. RM, 2 Sep 1987. 2q, St Helens, Powers Rivulet (= Ericksons Road, EQ938253), leg. NNTait etal, 20 Feb 1987.20, Ericksons Road, EQ938253', leg. RM, 11 Jun 1988, preserved 11 Jul 1988.

Etymology

The species is named after the Australian naturalist Charles Barret (1879-1959). Barrett (1938) pubished two phorographs of a live onychophoran with 15 pairs of legs which he identified as Ooperipatus insignis. The specimen "measured $11 / 4$ inches in length, and was of a delicate fawnbrown colour" (Barrett 1938). It had been sent to Barrett in Melboume from St Marys, Tasmania, which is ncar the known range of T. barretti. Unfortunately, the fate of Barrett's specimen, the exact locality of its capture and the name of the collector are unknown. We nevertheless believe that Barrett's is the first record of the onychophoran we name T. barretti.

\section{First Collection}

The first extant museum specimens were collected by RM at Terryvale Marsh (Ericksons Road, EQ938253) near St
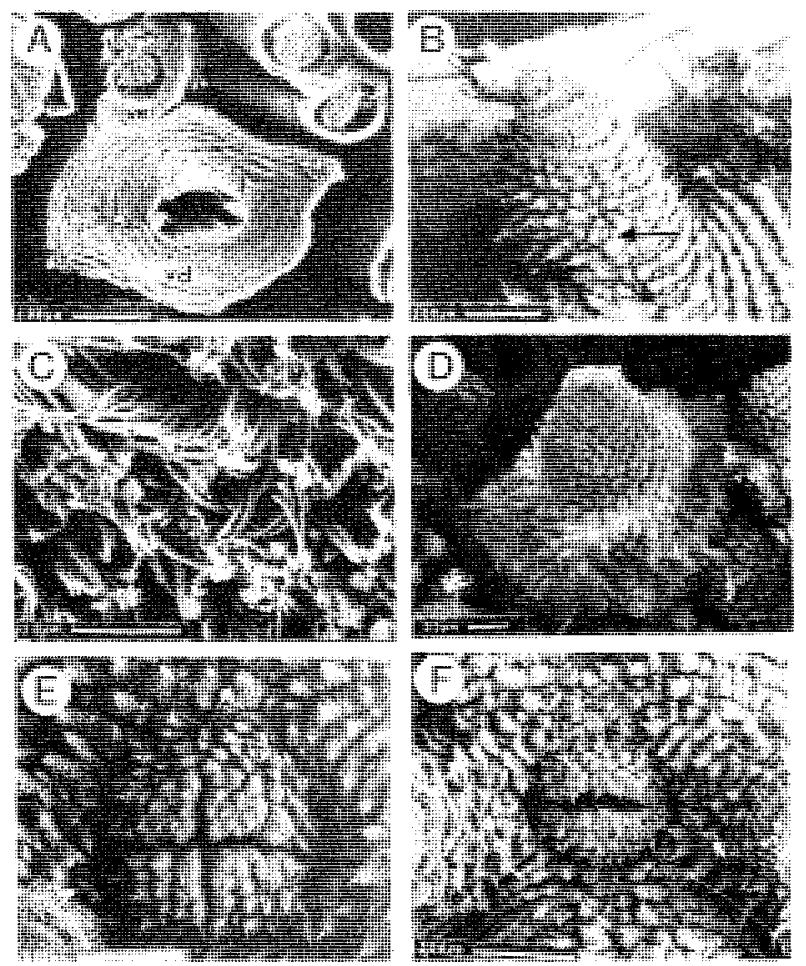

\section{PLATE 2}

Tasmanipatus barretti, gen. nov, sp. nov. (A) SEM of male genital tract showing vasa efferentia (ve) and vas deferens (vd). (B) SEM of sixth foot of a male; showing position of a crural papilla (arrow). (C) SEM of spermatozoa from the vas efferens. (D) SEM of crural papilla of a female, extended. (E) SEM of a cruciform male genital pore. (F) SEM of a transverse male genital pore. 
Helens, on 3 Nov 1984, and were lodged at the Tasmanian Museum and Art Gallery, Hobart (acquisition number J1930).

\section{Distribution}

For detailed distribution see Mesibov \& Ruhberg (1991: fig. 1).

\section{Diagnosis}

In life, dorsal surface pink-mauve with a darker median stripe, ventral surface mainly creamy-white. Distinct crural papillae in both sexes.

\section{Description}

Fifteen pairs of claw-bearing legs. Primary dorsal dermal papillae with 6-9 ranks of scales (plate $1 F$ ). Inner blade of jaw with 5-8 accessory teeth. Sex determination difficult without dissection (pl. 2E,F). Adults typically 35-40 mm long at rest, extending to $75 \mathrm{~mm}$ when walking. Male with genital pore variable (e.g. transverse slit (pl.2F) or cruciform (pl.2E); anal pore slits distinct. Female with distinct crural papillae on legs 6-12 in most paratypes, some females also with crural papillae on legs 13 and 14, and a homologue of the anterior accessory gland papilla on leg 15; only a pallid area evident in place of the male posterior accessory gland openings.
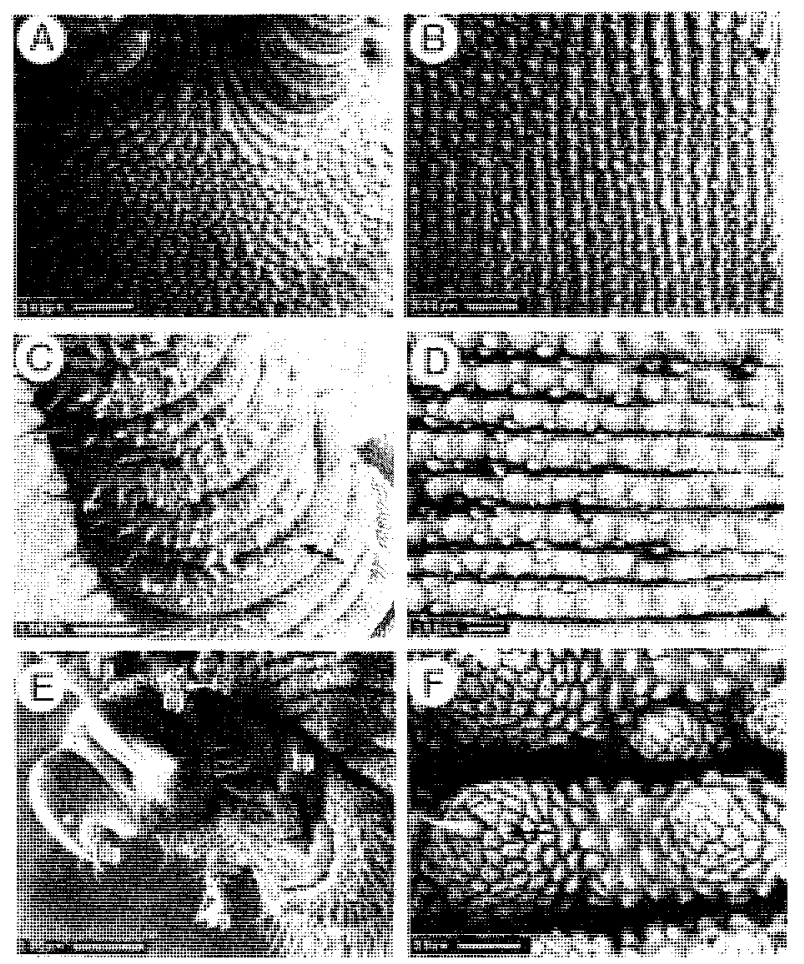

\section{PLATE 3}

Tasmanipatus anophthalmus, sp. nov. (A) SEM of the dorsal head without eyes. (B) SEM of 18 segmental plical folds (between arrow heads). (C) SEM of ventral antennal base with sensillae (arrow). (D) SEM of plical folds with bigger primary and smaller secondary papillae. (E) SEM of foot with two basal (bp) and three distal (dp) papillae. (F) SEM of primary dorsal papilla with six ranks of scales (arrow).

\section{Tasmanipatus anophthalmus sp. nov. (pls 3, 4)}

1989 "White Peripatus", Tait \& Briscoe, Aust. Nat. Hist. 22: 579 (including coloured photograph of live specimen).

1989 "Blind velvet worm". Local common name for this species.

1990 "Blind velvet worm", Mesibov, Tasforests 1991 (July 1990): $53-56$

1991 "Blind velvet worm", Mesibov \& Ruhberg, Pap. Proc. R. Soc. Tasm. 125: 11-16.

Holotype

8; Tasmania, Elephant Pass, FP035875, leg. R. Mesibov, 17 Jul 1988 (size in preservative $16.2 \mathrm{~mm}$ ). Collection of the Queen Victoria Museum and Art Gallery, Launceston.

\section{Paratypes}

13 , same data as for holotype (size $17.2 \mathrm{~mm}$; dissected).

1q, Lower Marsh Creek, FP052883, leg. RM, 17 Nov 1988 28, 1 , Catos Creek, EQ965030, leg. RM, 30 Oa 1988.2d, 1q, Lower Marsh Creek, FP052876, leg. RM, 2 Sep 1987. 20, Piccaninny Creek, FP020854, leg. RM, 19 Aug 1987. 20, Lower Marsh Creek, FP052876, leg. RM, 17 Aug 1987. 1 o", St Marys, Elephant Pass (= FP032890), leg. NN Tait et al., 19 Feb 1987.
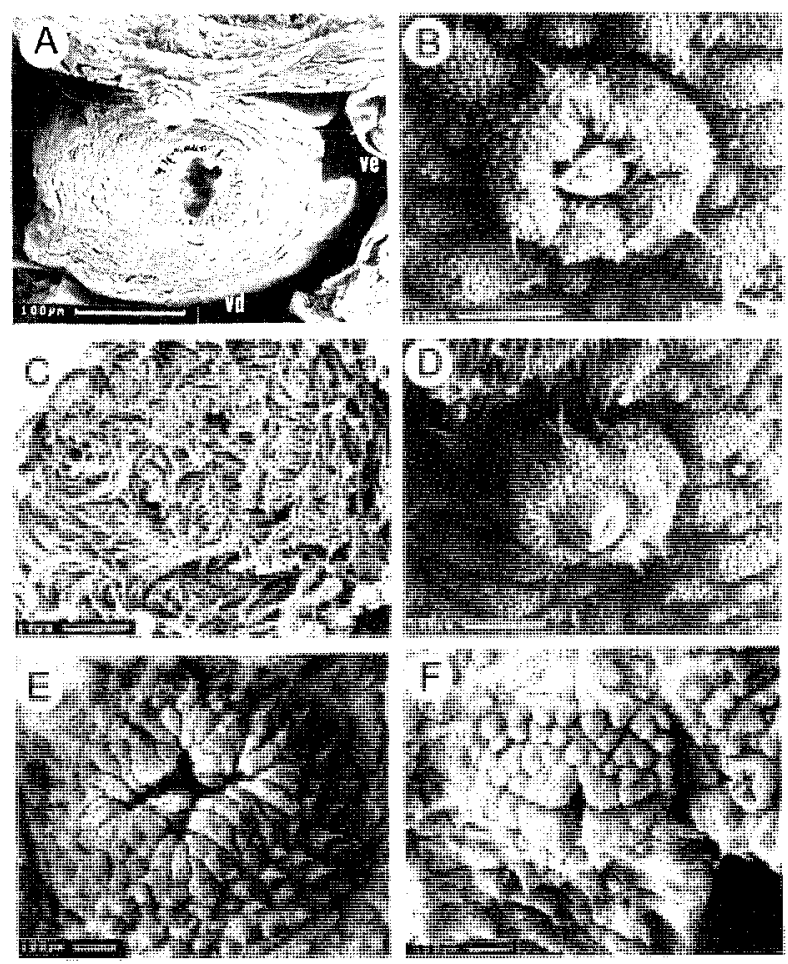

PLATE 4

Tasmanipatus anophthalmus, sp. nov. (A) SEM of a male genital tract showing vasa efferentia (ve) and vas deferens (vd). (B) SEM of sixth foot of a male, showing invaginated crural papilla. (C) SEM of spermatozoa from the vas efferens. (D) SEM of semi-protruded male crural papilla from a twelfth leg. (E) SEM of a cruciform male genital pore. (F) SEM of a cruciform male genital papilla in another male, and anterior accessory genital papilla (arrowhead). 
Etynology

Thespecies is named after its most characteristic feature, the lack of eyes.

Firs tcollection

T. anophthalmus was first collected by DBA, RM, NNT, K. Ackinson and R. Stutchbury at Elephant Pass and South Sister, near St Marys, on 19 February 1987.

Distribution

For detailed distribution see Mesibov \& Ruhberg (1991: fig. 1).

Diagnosis

Entirely unpigmented skin; no darker median stripe. "Tip of claws and entire jaws dark brown. No eyes. Distinct crural papillae in males only.

\section{Description}

Fifteen pairs of claw-bearing legs. Primary dorsal dermal papillae with 4-6 ranks of scales (pl. 3F). Inner blade of jaw with 5-6 accessory teeth. Sex determination easy without dissection (pl. 4E, F). Adults typically $25-30 \mathrm{~mm}$ long at rest, extending to $50 \mathrm{~mm}$ when walking. Male with genital pore mainly cruciform (pl. 4E,F); anal pore slits not very distinct. Female. all paratypes without distinct crural papillae.

\section{ACKNOWLEDGEMENTS}

The authors are grateful for financial support from the following sources: (to HR) the "Deutsche Forschungsgemeinschaft", grant: DFG Ru 358/1-5; (to RM) the Plomley Foundation (through the Queen Victoria Museum and Art Gallery) and the Australian Heritage Commission (through the Tasmanian Department of Lands, Parks and Wildlife
(TDLPW); and (to DAB and NNT) the World Heritage Area Directed Research Grant Fund (through the TDLPW), the Australian Research Council and the Macquarie University Research Grant Fund. For assistance in arranging fieldwork DAB and NNT thank Dr Stephen Smith, TDLPW. For assistance in collecting specimens in February 1987, DAB, RM and NNT are grateful to K. Atkinson and R. Stutchbury. For the loan of museum specimens HR is indebted to Dr R. Green, Curator of Zoology at the Queen Victoria Museum and Art Gallery. Finally, for constructive criticism of the manuscript we thank Drs D.T. Anderson, Michael Gray, B. Jamieson, George McKay and Hannelore Paxton. The senior author would like to thank Mrs R. Walter, Hamburg, for skilful technical assistance at the scanning electron microscope.

\section{REFERENCES}

Barret, C., 1938: A note on Peripatus. Vict. Nat. 55: 11-12.

Mesibov, R., 1990: Velvet worms: a special case of invertebrate fauna conservation. Tasforests 2: 53-56.

Mlisibov, R. \& Rlibirkg., 1991: Ecology and conservation of Tasmanipatus barretti and T. anophthalmus, parapatric onychophorans (Onychophora: Peripatopsidae) from northeastern Tasmania. Pap. Proc. R. Soc. Tasm. 125: 1116.

Ruhberg, H., 1985: Die Peripatopsidae (Onychophora). Systematik, Okkologie, Chorologie und phylogenetische Aspekte. In Schaller, F. (Ed.): ZOOLOGIE, Heft 137. E. Schweizerbart'sche Verlagsbuch handlung, Stuttgart: 1-184.

Ruhiserg, H., Tair, N.N., Briscoe, D.A. \& Siorch, V., 1988 Cephalofovea tomahmontis n. gen., n. sp., an Australian peripatopsid (Onychophora) with a unique cephalic pit. Zool. Anz. 221: 117-133.

Talt, N.N. \& Briscot, D.A., 1989: Peripatus - up here for thinking? Aust. Nat. Hist. 22: 574-579.

(accepted 7 December 1990) 